УДК 504.062.4(470.341)

ОЦЕНКА ЭФФЕКТИВНОСТИ РЕАЛИЗАЦИИ ПРИОРИТЕТНОГО

ФЕДЕРАЛЬНОГО ПРОЕКТА «ОЗДОРОВЛЕНИЕ ВОЛГИ»

НА РЕГИОНАЛЬНОМ УРОВНЕ В УСЛОВИЯХ НИЖЕГОРОДСКОЙ ОБЛАСТИ

${ }^{1}$ Копосова Н.Н., ${ }^{1}$ Вершинина И.В., ${ }^{2}$ Хоботилова Е.И.

${ }^{1}$ ФГБОУ ВО «Нижегородский государственный педагогический университет имени Козьмы Минина», Нижний Новгород, е-mail: coposowa.nataliya@yandex.ru;

${ }^{2}$ Министерство экологии и природньх ресурсов Нижегородской области,

Нижний Новгород, е-mail: lena.hobotilova97@yandex.ru

В работе рассмотрены основные направления, цели, планируемые и достигнутые результаты приоритетного федерального проекта «Оздоровление Волги» на уровне Приволжского Федерального округа в условиях Нижегородской области. Отмечается, что данный проект имеет особую актуальность для Нижнего Новгорода и области, поскольку вода в реке Волге на данной территории относится к категории «грязная» и «загрязненная», при этом вода из реки является одним из основных источников питьевой воды для жителей г. Нижнего Новгорода и Нижегородской области. На территории Нижегородской области федеральный проект осуществляется путем реализации регионального проекта «Сохранение и предотвращение загрязнения реки Волги на территории Нижегородской области». Основные целевые показатели регионального проекта соответствуют таковым на федеральном уровне и заключаются в снижении количества загрязненных сточных вод, поступающих в реку Волгу; увеличении степени очистки сточных вод путем модернизации и строительства новых очистных сооружений на территории Нижнего Новгорода и области; уменьшении степени ненативного воздействия потенциально опасных для реки Волги объектов ранее накопленного экологического ущерба. Результатом реализации федерального проекта «Оздоровление Волги» в 2021 г. явилось увеличение мощности очистных сооружений, вследствие чего сброс сточных вод сократился на 0,19 км³. В Нижнем Новгороде осуществление проекта идет путем опережающих темпов проведения отдельных мероприятий, при этом достижение целевых показателей федерального проекта происходит без значительного улучшения экологического состояния воды реки Волги. Повысить эффективность осуществления проектных решений возможно при пересмотре приоритетных задач проекта «Оздоровление Волги» и разработки долгосрочной стратегии развития бассейна.

Ключевые слова: федеральный проект, река Волга, загрязнение, сточные воды, планируемые показатели

\title{
ESTIMATION OF THE EFFICIENCY OF IMPLEMENTATION OF THE PRIORITY FEDERAL PROJECT «RECOVERY OF THE VOLGA» AT THE REGIONAL LEVEL IN THE CONDITIONS OF THE NIZHNY NOVGOROD REGION
}

\author{
${ }^{1}$ Koposova N.N., ${ }^{1}$ Vershinina I.V., ${ }^{2}$ Khobotilova E.I. \\ ${ }^{1}$ Minin Nizhny Novgorod State Pedagogical University, Nizhny Novgorod, \\ e-mail: coposowa.nataliya@yandex.ru; \\ ${ }^{2}$ Ministry of Ecology and Natural Resourcesof the Nizhny Novgorod Region, \\ Nizhny Novgorod, e-mail: lena.hobotilova97@yandex.ru
}

\begin{abstract}
The paper considers the main directions, goals, planned and achieved results of the priority federal project «Improvement of the Volga» at the level of the Volga Federal District in the conditions of the Nizhny Novgorod region. It is noted that this project is of particular relevance for Nizhny Novgorod and the region, since the water in the Volga River in this area is classified as «dirty» and «polluted», while water from the river is one of the main sources of drinking water for residents of Nizhny Novgorod and the Nizhny Novgorod region. uOn the territory of the Nizhny Novgorod region, the federal project is carried out through the implementation of the regional project «Preservation and prevention of pollution of the Volga River in the territory of the Nizhny Novgorod region». The main targets of the regional project are in line with those at the federal level and are to reduce the amount of polluted wastewater entering the Volga River; increasing the degree of wastewater treatment through the modernization and construction of new treatment facilities in the territory of Nizhny Novgorod and the region; reducing the degree of adverse impact of objects of previously accumulated environmental damage potentially dangerous for the Volga River. The implementation of the Volga Rehabilitation federal project in 2021 resulted in an increase in the capacity of treatment facilities, as a result of which wastewater discharge decreased by $0.19 \mathrm{~km} 3$. In Nizhny Novgorod, the implementation of the project is proceeding at an outstripping pace of individual activities, while the achievement of the target indicators of the federal project occurs without a significant improvement in the ecological state of the Volga River water. It is possible to increase the efficiency of the implementation of design solutions by revising the priority tasks of the Volga Rehabilitation project and developing a long-term strategy for the development of the basin.
\end{abstract}

Keywords: federal project, Volga river, pollution, waste water, planned indicators

Экологическая обстановка на территории Российской Федерации свидетельствует о том, что ситуация в области охраны окружающей среды остается неблагополуч- ной, а уровень загрязнения природной среды - высоким даже в условиях систематического осуществления ряда мероприятий в области охраны окружающей среды, в том 
числе снижения сбросов и выбросов загрязняющих веществ на фоне снижения производственных мощностей. В частности, на сегодняшний день в бассейне реки Волги сложилась очень напряженная экологическая ситуация, что обусловлено в основном загрязнением реки. В воды бассейна реки Волги поступают коммунально-бытовые и промышленные сточные воды, содержащие загрязняющие вещества различного химического состава [1-3]. Поступающие вещества снижают качество воды, являются опасными для водной экосистемы, а также оказывают негативное влияние на водные биологические ресурсы и их местообитание [4]. Нижний Новгород входит в число городов, где качество воды соответствует критериям «загрязненная» и «грязная», при этом воды реки Волги представляют собой один из основных источников питьевого водоснабжения как для Нижнего Новгорода, так и для ряда городов Приволжского Федерального округа.

Целью исследования явилась оценка эффективности и возможности оптимизации проводимых мероприятий приоритетного федерального проекта «Оздоровление Волги» на территории Нижегородской области.

\section{Материалы и методы исследования}

С целью реализации п. 7 Указа Президента «О национальных целях и стратегических задачах развития Российской Федерации на период до 2024 года» разработан национальный проект «Экология», в структуре которого отражен перечень мероприятий по экологическому улучшению состояния водных объектов, в том числе реки Волги. На сегодняшний день комплексный подход к улучшению экологического состояния реки реализуется посредством осуществления федерального проекта «О3доровление Волги», который направлен на оздоровление реки Волги, являющейся крупнейшей рекой России, бассейн которой располагается на территории 38 субъектов Российской Федерации, при этом в федеральном проекте участвуют только 16 субъектов. В рамках федерального проекта разработан региональный проект «Сохранение и предотвращение загрязнения реки Волги на территории Нижегородской области», в котором предусмотрено сохранение бассейна реки Волги путем снижения объема сточных вод ненормативного качества за счет модернизации имеющихся и строительства современных очистных сооружений, а также осуществления мероприятий по снижению воздействия накопленного экологического вреда окружающей среде (территория Бурнаковской низины) [5].

Региональный проект направлен на достижение 3 основных целевых показателей:

- снижение объема отводимых в реку Волгу загрязненных сточных вод (с 0,35 км ${ }^{3}$ в 2019 г. до 0,12 км³ в 2024 г.);

- обеспечение увеличения мощности очистных сооружений, обеспечивающих очистку сточных вод;

- извлечение и утилизация затонувших и брошенных плавательных средств [5].

Ключевые мероприятия регионального проекта заключаются в составлении проектно-сметной документации по строительству и модернизации очистных сооружений на территории области.

Методом исследований является анализ проектных решений нормативной документации федерального и регионального уровня, утвержденной государственными структурами в области управления природопользованием, с последующей оценкой степени эффективности реализации мероприятий в рамках осуществления проекта.

\section{Результаты исследования и их обсуждение}

С целью снижения поступления сточных вод ненадлежащего качества в бассейн реки Волги в рамках реализации регионального проекта проведены мероприятия по модернизации и оптимизации очистных сооружений на наиболее значимых предприятиях водоочистного комплекса Нижегородской области, что позволяет осуществить дополнительную очистку сточных вод. На предприятии «Нижегородский водоканал» осуществлена модернизация аэротенков очистных сооружений с заменой системы подачи активного ила на Нижегородской станции аэрации. В г. Дзержинске Нижегородской области в ОАО «Дзержинский водоканал» проведена реконструкция районных очистных сооружений с коллекторами очищенных стоков и строительством канализационно-насосной станции. Проведенные мероприятия по оптимизации и модернизации очистных сооружений позволили осуществить доочистку сточных вод в объеме 246 млн м ${ }^{3}$ в год на «Нижегородском водоканале» и 20 млн м ${ }^{3}$ в год на «Дзержинском водоканале».

В структуре паспорта федерального проекта «Оздоровление Волги» имеется функциональное направление «Ликвидация 
(рекультивация) объектов негативного воздействия, в том числе объектов накопленного экологического вреда, представляющих угрозу реке Волга». Помимо этого, проектом предусмотрены разработка концепции по снижению поступлений загрязняющих веществ с естественных ландшафтов селитебных территорий, земель сельскохозяйственного назначения, предприятий животноводческого комплекса, промышленных площадок предприятий, полигонов захоронения отходов и свалок, объектов транспортной инфраструктуры и внедрение указанной концепции в пилотных регионах. На рисунке представлен анализ результатов реализации задач федерального проекта «Оздоровление Волги» в динамике за 4 года осуществления приоритетного проекта.

На основании данных отчета о реализации целей и задач федерального проекта по оздоровлению воды в реке Волге в первом квартале 2021 г. достигнут ряд положительных результатов:

1) завершены строительство и реконструкция 41 объекта очистных сооружений, в результате чего обеспечено количественное сокращение сброса загрязненных

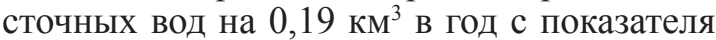

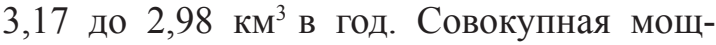
ность новых, а также модернизированных очистных сооружений обеспечила достижение проектного показателя 2020 г. Сброс сточных вод сокращен на 0,19 км ${ }^{3}$ в год;

2) в регионах активно проводится работа по выявлению бесхозных объектов негативного воздействия на реку Волгу (затопленных, полузатопленных, брошенных в береговой полосе плавсредств и их остатков). Утилизация данных объектов запланирована на 2022-2024 гг.;
3) мероприятия, направленные на ликвидацию объектов накопленного экологического вреда, негативно влияющих на состояние реки Волги, запланированы на последний квартал 2021 г;

4) на территории реализации федерального проекта Росприроднадзором регулярно проводятся контрольно-надзорные мероприятия по выявлению несанкционированных источников сброса сточных вод, в том числе осуществляется инвентаризация объектов ЖКХ и промышленных предприятий, расположенных на территориях, прилегающих к Волге; установлен перечень объектов, оказывающих негативное влияние на Волжский бассейн;

5) в 2019 г. Институтом Водных проблем разработана концепция по снижению диффузного загрязнения водных объектов. В ходе разработки концепции был осуществлен анализ роли неконтролируемых диффузных источников в загрязнении водных объектов бассейна Волги, нормативно-правовой базы в вопросах регулирования диффузного загрязнения, а также разработаны новые методы количественной оценки диффузного загрязнения реки Волги от различных источников и сформулированы рекомендации по планированию и проведению наиболее эффективных мероприятий для снижения воздействия диффузных источников на качество воды реки Волги.

Выполнение плановых и целевых показателей приоритетного проекта федерального уровня «Оздоровление Волги» на территории Нижнего Новгорода и области осуществляется посредством реализации регионального проекта «Сохранение и предотвращение загрязнения реки Волги на территории Нижегородской области» $[6,7]$.

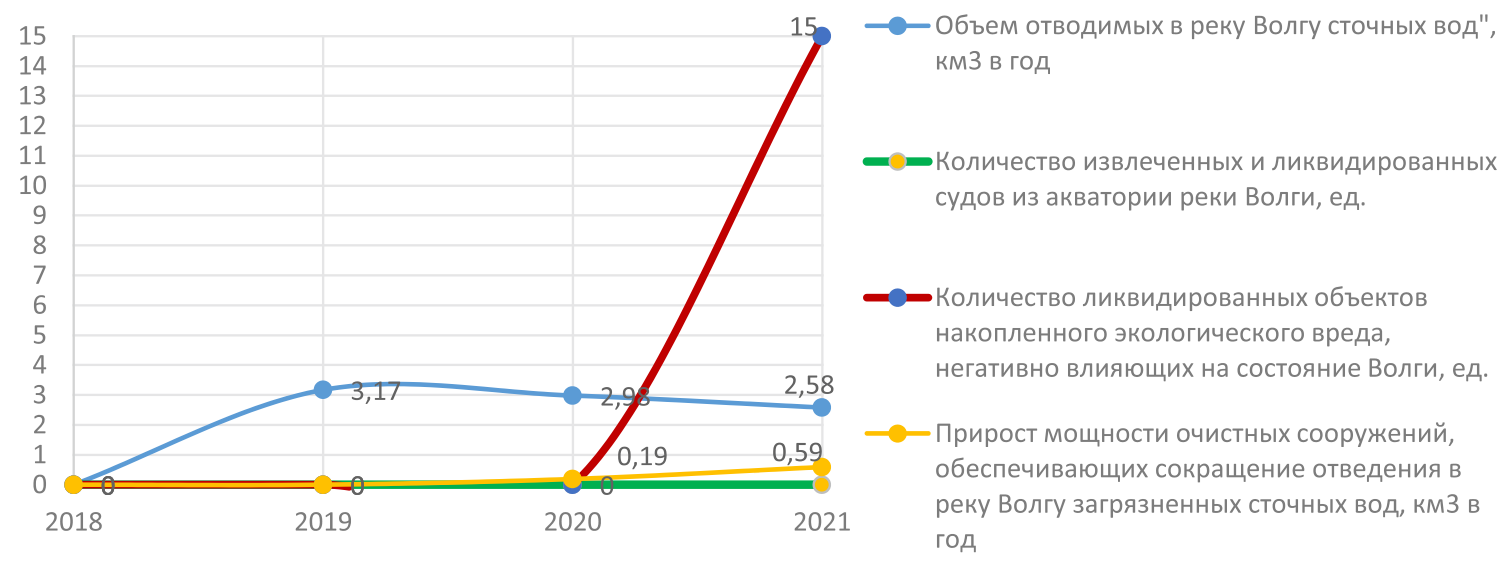

Результаты реализащии федерального проекта «Оздоровление Волги» 
Нижегородская область является одним из лидеров по реализации проекта «Оздоровление Волги». В рамках достижения регионального показателя «Количество извлеченных и ликвидированных судов из акватории реки Волги» запланирована утилизация 5 объектов на период с 2022 по 2024 гг. По результатам инвентаризации установлены все затонувшие и полузатонувшие суда в акватории и на берегах реки Волги и ее притоков. Таким образом, выявлено, что на территории Нижегородской области в затопленном (полузатопленном) состоянии, а также в границах береговой полосы находятся 39 объектов (понтонов, корпусов барж и дебаркадеров, неизвестных плавсредств и их остатков). Помимо этого, на территории Нижегородской области реализуется федеральный показатель «Проведение контрольно-надзорных мероприятий». Надзорные мероприятия по выявлению несанкционированных источников сброса сточных вод проводятся Межрегиональным управлением Росприроднадзора по Нижегородской области и Республике Мордовия с августа 2018 г. В рамках задач, установленных центральным аппаратом Росприроднадзора на территории Нижегородской области, был проведен целый комплекс мероприятий с 2018 г. по текущий период 2021 г. В процессе проводимой работы в рамках регионального проекта особое внимание уделяется объектам накопленного экологического вреда, расположенным в водоохранной зоне реки Волги. Под понятие «объект накопленного экологического ущерба» попадает территория Бурнаковской низины, где регулярно наблюдается вынос в реку Волгу нефтепродуктов [8, 9]. Суммарная степень загрязнения почвенного покрова территории Бурнаковской низины относится к категории «чрезвычайно опасная».

Министерством экологии и природных ресурсов Нижегородской области проводится работа по обоснованию включения мероприятий по ликвидации загрязненной территории Бурнаковской низины в региональный проект «Оздоровление реки Волги».

Комплекс мероприятий проекта на региональном уровне способствует:

- улучшению санитарного и экологического состояния реки Волги;

- уменьшению антропогенного воздействия на водные объекты Волжского бассейна, расположенные на территории Нижегородской области;

- предотвращению загрязнения, заиления водных объектов и истощения их вод;
- сохранению среды обитания водных биологических ресурсов и гидробионтов на территории населенных пунктов Нижегородской области в границах Волжского бассейна;

- снижению поступления загрязнения от неконтролируемых диффузных источников, поступающих в водные объекты в бассейне реки Волги;

- устранению объектов накопленного экологического вреда (территория Бурнаковской низины);

- повышению качества питьевой воды;

- формированию бережного отношения к реке Волге.

На текущий момент показатели регионального проекта не имеют отклонений от показателей федерального проекта преимущественно за счет опережающих темпов проведения мероприятий по проекту, при этом регион занимает первое место по количеству строящихся объектов очистных сооружений. Несмотря на достижение плановых показателей, реализация данного проекта сопровождается рядом неблагоприятных тенденций. В частности, установлено, что в региональный паспорт были отобраны проекты, на которые имелась разработанная проектная документация, при этом они не являются крупными объектами негативного воздействия. Таким образом, введение в эксплуатацию таких объектов существенно не влияет на изменение качества воды в реке Волге. Анализ документации, отражающей реализацию проекта, выявил проблемы, которые могут повлиять на конечный результат проекта: недостаточность и нерегулярность финансирования, низкое качество осуществляемых мероприятий, разработка проекта без учета инвентаризации объектов негативного воздействия и недостаточность планируемого государственного мониторинга, формальность концепции по сокращению поступления диффузного стока.

Для оптимизации сложившейся ситуации необходимо пересмотреть приоритетность мероприятий по проекту, предварительно осуществив учет объектов негативного воздействия в бассейне р. Волги, а также внести изменения в части критериев отбора мероприятий в проект и их финансирования, нормативов качества сбрасываемых сточных вод, рассмотреть возможность включения в проект реализации мероприятий, разработанных в рамках концепции по снижению диффузного стока. В целях повышения эффективности дости- 
жения результатов проекта и мониторинга реки Волги возможна реализация «онлайнкарты» экологического состояния реки Волги в условиях Нижегородской области. Полученные результаты позволят отслеживать уровень загрязнения реки Волги в реальном времени. Реализация данных мероприятий послужит дополнительным источником объективных данных о масштабах и характере загрязнения в целях расстановки приоритетов при выделении исполнительными органами власти ресурсов на планомерное осуществление задач проекта «Оздоровление Волги».

\section{Выводы}

Федеральный проект «Оздоровление Волги» в Нижегородской области выполняется с 2018 г. на основе регионального проекта «Сохранение и предотвращение загрязнения реки Волги на территории Нижегородской области». Анализ комплекса мероприятий, входящих в состав проекта «Оздоровление Волги» на федеральном и региональном уровне, показал, что ключевым показателем реализации проекта является снижение объема отводимых в реку Волгу загрязненных сточных вод в 3 раза. На текущий момент планируемые к достижению показатели федерального проекта «Оздоровление Волги» реализованы, но при этом не в полном объеме соответствуют проектным решениям. Основные проблемные моменты реализации проекта обусловлены недостаточным комплексом проводимых мероприятий, в частности не предусмотрены механизмы решения проблемы диффузного стока, оказывающего существенный вклад в загрязнение вод реки Волги.

Достигнутые целевые показатели на региональном уровне обоснованы опережающими темпами проведения отдельных мероприятий по проекту, при этом имеются негативные тенденции и текущие проблемные вопросы по реализации проекта, в случае отсутствия решения по которым эффективность реализуемого проекта будет значительно ниже и дальнейшие планируемые результаты могут быть не достигнуты. Повысить эффективность осуществления проектных решений возможно при пересмотре приоритетных задач проекта «Оздоровление Волги», обязательном учете объектов негативного воздействия в бассейне реки Волги, реализации концепции по сокращению поступления диффузного стока и определению источников финанси- рования мероприятий, а также при систематическом экологическом мониторинге состояния и загрязнения водных объектов бассейна реки Волги.

\section{Список литературы / References}

1. Козлов А.В., Уромова И.П. Уровень эколого-гидрохимических свойств воды волги и оки в условиях городской территории // Успехи современного естествознания. 2020. № 12. C. 93-97.

Kozlov A.V., Uromova I.P. level of ecological and hydrochemical properties of water of the volga and the oka rivers in conditions of urban territory // Uspekhi sovremennogo estestvoznaniya. 2020. № 12. P. 93-97 (in Russian).

2. Краснов А.Н. Проблемы Чебоксарского водохранилища - Проект «Отметка 68» // Материалы Международной научно-практической конференции «Экологическое образование для устойчивого развития: теория и педагогическая реальность». Н.Новгород: ООО Типография «Поволжье», 2013. C. 373-381

KrasnovA.N.Problems of the Cheboksary reservoir-Project «Mark 68» // Materialy Mezhdunarodnoj nauchnoprakticheskoj konferencii «Ekologicheskoe obrazovanie dlya ustojchivogo razvitiya: teoriya i pedagogicheskaya real'nost'». N.Novgorod: OOO Tipografiya «Povolzh'ye», 2013. P. 373-381 (in Russian).

3. Исенаилева Ж.Н., Волкова И.В. Оценка качества среды аквальных комплексов дельты р. Волги // Международный журнал прикладных и фундаментальных исследований. 2012. № 1-1. C. 89-89.

Isenaileva Zh.N., Volkova I.V. Assessment of the quality of the environment of the water complexes of the Volga Delta // Mezhdunarodnyj zhurnal prikladnyh i fundamental'nyh issledovanij. 2012. № 1-1. P. 89-89 (in Russian).

4. Раткович Л.Д., Маркин В.Н., Глазунова И.В., Соколова С.А. Факторы влияния диффузного загрязнения на водные объекты // Природообустройство. 2016. № 3. С. 64-75.

Ratkovich L.D., Markin V.N., Glazunova I.V., Sokolova S.A. Factors of influence of diffuse pollution on water bodies // Prirodoobustroistvo. 2016. № 3. P. 64-75 (in Russian).

5. Паспорт «Сохранение и предотвращение загрязнения реки Волги на территории Нижегородской области». 2018. 19 c.

Passport «Preservation and prevention of pollution of the Volga River in the territory of the Nizhny Novgorod region». 2018. 19 p. (in Russian).

6. Сведения о достижении результатов, контрольных точек и мероприятий. Отчет Министерства экологии и природных ресурсов Нижегородской области. 2019. 7 с.

Information on the achievement of results, milestones and events. Report of the Ministry of Ecology and Natural Resources of the Nizhny Novgorod Region. 2019.7 p. (in Russian).

7. Отчет о ходе реализации регионального проекта Нижегородской области «Оздоровление Волги». Письмо Министерства экологии и природных ресурсов Нижегородской области. 2019.3 c.

Report on the implementation of the regional project of the Nizhny Novgorod Region «Improvement of the Volga». Letter from the Ministry of Ecology and Natural Resources of the Nizhny Novgorod Region. 2019. 3 p. (in Russian).

8. Минэкологии региона направило заявку на включение Бурнаковской низины в государственный реестр объектов накопленного вреда. [Электронный ресурс]. URL: http:// mineco-nn.ru (дата обращения: 02.12.2021).

The Ministry of Ecology of the region sent an application for inclusion of the Burnakovsky lowland in the state register of objects of accumulated harm. [Electronic resource]. URL: http:// mineco-nn.ru (date of access: 02.12.2021) (in Russian).

9. Козлов А.В., Клочков Е.А., Береснев А.А., Захарова А.А., Козлова Е.С. Эколого-гидрохимическая оценка водоемов в условиях функционирования нефтехранилищ и комплексных техногенных объектов Нижегородского региона // Успехи современного естествознания. 2021. № 6. С. 75-81.

Kozlov A.V., Klochkov E.A., Beresnev A.A., Zakharova A.A., Kozlova E.S Environmental and hydrochemical assessment of water bodies in conditions of operation of oil storage facilities and complex technogenic facilities of Nizhny Novgorod region // Uspekhi sovremennogo estestvoznaniya. 2021. № 6. P. 75-81 (in Russian). 